"This is an Accepted Manuscript of an article published by Taylor \& Francis in Journal of Sports Sciences on 25 Apr 2018, available online

\title{
Strategies of Parkour practitioners for executing soft precision landings
}

\begin{abstract}
Parkour landing techniques differ from performances of other sports as they are practiced in urban spaces with uncontrolled surfaces and drop heights. Due to the relatively young age of the sport, few studies have tried to understand how practitioners -- called traceurs -- succeed at performing these dynamic performances. In this paper, we focus on the precision landing technique, which has a fundamental role in most of the Parkour motions. We analyzed the lower limbs motion of traceurs executing the precision landings from two different heights and compared their performance with untrained participants. We found that traceurs perform a soft landing extending its duration twice than untrained participants do $(p<.001)$, increasing the range of motion $(p<.001)$ and generating more mechanical energy $(p<.01)$ to dissipate the impact. In the Parkour technique, the knee accounted for half of the energy dissipated. The peak joint torques $(p<.001)$ and power $(p<.0001)$ were reduced in the Parkour technique. The increase of the landing height did not modify the proportion of individual joint mechanical energy contribution for dissipation. Our results could be used to enhance Parkour performance, and to understand new ways in which sport practitioners can land in order to prevent injuries.
\end{abstract}

Keywords: Drop jump, traceurs, sports performance, eccentric contraction, energy dissipation 


\section{Introduction}

Parkour is a lifestyle sport in which practitioners -- called "traceurs" -- have to overcome obstacles in the environment in the most efficient manner and where movements look risky, highly dynamic and complex (Kidder, 2012; Gilchrist \& Wheaton, 2011; Cazenave \& Michel 2008). One frequent and critical Parkour motion is landing which is commonly performed in urban spaces, onto a large variety of surfaces and from different drop heights. Parkour precision landing technique is used for short dropping heights and requires practitioners to land and stay with precision on their forefoot without heel contact with the ground, to flex their lower limb joints without any varus-valgus motion of the knees and to use their arms to counterbalance the movement and stabilize themselves (Figure 1).

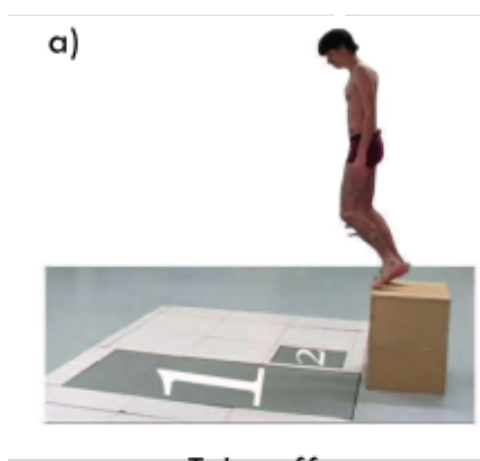

Take-off

b)

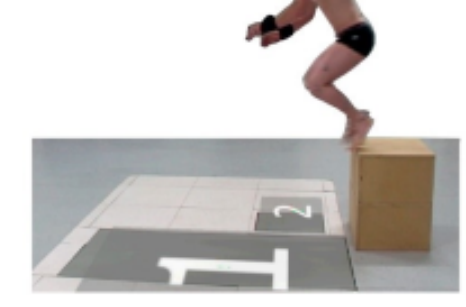

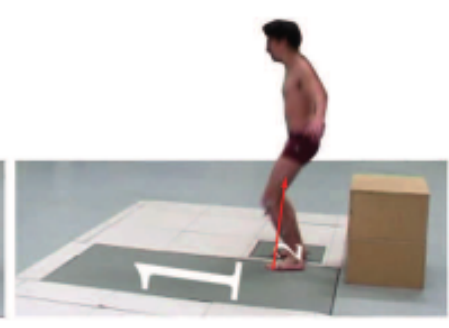

Initial Contact

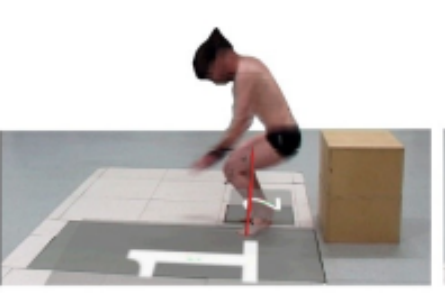

Max knee flexion
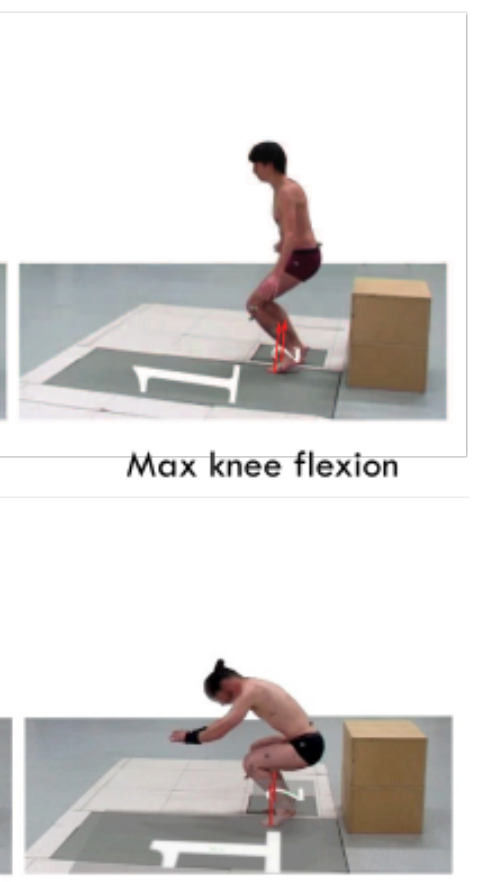

Figure 1. In a), an untrained landing trial. In b), a precision landing trial. The landings were performed from $60 \mathrm{~cm}$ height. The landing phase starts at initial contact with the ground (when the reaction force is more than $50 \mathrm{~N}$ ) and ends at maximum knee flexion. 
It has been reported that bad executions of Parkour landings are the principal cause of injury in this discipline, accounting for $61 \%$ of the cases (Wanke, Thiel, Groneberg, \& Fischer, 2013). In fact, high Ground Reaction Forces (GRF) may lead to bone injury at the lower limbs (See (Gittoes, \& Irwing 2012) for a review). Nevertheless, biomechanical studies assessing the kinetics of Parkour (Puddle, \& Maulder 2013; Standing, \& Maulder 2015) landings have shown that traceurs are able to decrease the peak vertical GRF. According to the literature (Devita, \& Skelly 1992) a knee flexion of more than 90 degrees from full extension corresponds to a soft landing, otherwise it is classified as a stiff landing. If GRF peaks are lowered and the landing is soft, then joint torques and joint power peaks might also be lowered by traceurs executing precision landings. These dynamic characteristics are also important for injury prevention (Devita, \& Skelly 1992; Bisseling, Hof, Bredeweg, Zwerver, \& Mulder, 2007; Bisseling, Hof, Bredeweg, Zwerver, \& Mulder, 2008; Rosen, Ko, Simpson, Kim, \& Brown, 2015) and might be of interest in other highly dynamic and complex sports such as gymnastics.

Moreover, Parkour requires rigorous training (Grosprêtre, \& Lepers, 2016). It has been shown that Parkour training induces high development of muscular capacity like power or eccentric forces (Marchetti et al. 2012) and that traceurs can develop high eccentric joint torques in the knees when performing long jumps (Grosprêtre, \& Lepers, 2016). Therefore, quantifying the contribution of joints in energy dissipation might provide clues about how the lower extremity muscles should be conditioned to execute precision landings.

In this research, we compare the Parkour precision landing with the landings performed in a natural style by untrained participants from two different heights. To the best of the authors knowledge, only kinetic studies of Parkour landings have been carried out and no study has quantified and compared the kinematics, dynamics and energetics of Parkour precision landings 
between traceurs and untrained participants. We hypothesized that traceurs should perform soft landings which induce an extended landing phase duration for energy dissipation and thus, lead to more mechanical energy dissipation. Furthermore, we expected that traceurs would use especially the knee to absorb the energy as it was observed by studies on soft landings (Devita, \& Skelly 1992). Moreover, we hypothesized that the Parkour technique would induce a reduction of lower extremity joint torque and power because of the soft landing that traceurs seem to perform and their ability to lower the vertical GRF. Lastly, we expected that increasing the landing height will induce an increment of the assessed variables in both groups except for the body configuration at initial contact with ground (joint angles of the hip, knee and ankle).

\section{Material and Methods}

\section{Participants}

Twelve healthy untrained male participants (age: $22.3 \pm 3.3 \mathrm{y}$, height: $1.79 \pm 0.08 \mathrm{~m}$, mass: $71.2 \pm 5.6 \mathrm{~kg}$ ) and twelve healthy trained male traceurs (age: $22.2 \pm 4.8 \mathrm{y}$, height: $1.73 \pm 0.04 \mathrm{~m}$, mass: $66.6 \pm 5.1 \mathrm{~kg}$ ) volunteered for this study. The traceurs' experience in Parkour practice was $5.4 \pm 2.1$ y. The subject exclusion criterion was based on history of lower extremity injuries or diseases that might affect landing biomechanics. The experiments were conducted in accordance with the standards of the Declaration of Helsinki (rev. 2013) and approved by a local ethics committee.

\section{Procedures}

All participants started with $5 \mathrm{~min}$ of warming up that was followed by 5 min of selfstretching. Two boxes of $30 \mathrm{~cm}$ height were used to achieve two landing heights from $30 \mathrm{~cm}$ and $60 \mathrm{~cm}$ (Figure 1). For each height, 2 blocks of 3 successful trials without randomization were 
executed as follows: one block of familiarization, followed by a second one of recordings including 30 seconds of rest in between. Untrained participants' trials were labeled as untrained trials while Parkour trials were labeled Parkour trials. All participants were instructed to land barefoot in a specified target and to avoid jumping up to not exceed the initial height. No instruction was provided regarding the use of the arms. The target was set with marker landmarks placed on the landing surface to limit the minimal and maximal horizontal landing distance at $50 \pm 5 \mathrm{~cm}$. In the Parkour trials, traceurs were instructed to land using the Parkour precision technique (Figure 1). In the untrained trials, participants were asked to land freely using the both feet together and to stabilize themselves on the force platform as they did not know how to perform precision landings.

Kinematic data were collected using 12 infrared cameras sampling at $200 \mathrm{~Hz}$ (Vicon, Oxford Metrics, Oxford, UK) and recording 22 reflective markers placed on the subject's lowerlimbs. Two force plates (AMTI, Watertown, MA, USA) embedded into the floor were used to record GRF and moments at $2000 \mathrm{~Hz}$ for each limb. Markers were set based on $\mathrm{Wu}$ recommendations (Wu et al., 2002) as follows: the first and fifth metatarsal, calcaneus, lateral and internal malleolus, anterior tibial tuberosity, lateral and medial epicondyles of knee, greater trochanter, posterior superior iliac spine and anterior superior iliac spine.

Kinematics and GRFs were filtered at the same cutoff frequency (Kristianslund, Krosshaug, \& Van den Bogert, 2012; Mccaw, Gardner, Stafford, \& Torry, 2013) with a low-pass Butterworth digital filter of 4th order applied in a zero-phase. A cut-off frequency of $30 \mathrm{~Hz}$ was used after a residual analysis (Winter, 2009). Scaling parameters were computed according to Dumas (Dumas, Cheze, \& Verriest, 2007). Inverse kinematics and inverse dynamics were performed using OpenSim (Delp et al., 2007). Results were analyzed with custom made algorithms in order to compute joint power and mechanical work, evaluate the data and perform the statistical analysis. 
Data were analyzed during the landing phase. The landing phase was defined between the IC $(0 \%)$ (defined as the time instant when vertical GRF was more than $50 \mathrm{~N}$ (Standing and Maulder, 2015)), and the maximum knee flexion (100\%). In this study, we refer to this time interval as the "landing phase duration". Hip, knee and ankle relative joint angular configurations (Euler XYZ body-fixed rotation angles and body-segmental reference frames according to Delp et al., (1990)) at initial contact with the ground "IC", Range Of Motion (RoM) of the joints, total time of the landing phase, joint torques, joint power and the eccentric mechanical joint work were also evaluated. Mechanical work calculation included the individual joint contribution to energy.

GRF, joint torques, joint power and mechanical work were normalized by the subject's body mass. Joint power was computed as the scalar product of the joint torque vector and the joint angular velocity vector. Joint mechanical work was calculated as the eccentric work used for decelerating the lower extremity segments by integrating the negative joint power. The work contribution for energy dissipation was calculated by normalizing the calculated joint work by the total work (summation of the hip, knee and ankle eccentric work previously calculated) and multiplying by 100 . Results were reported for the dominant leg as it has been reported to provide better conclusions for injury prevention (Niu, Wang, He, Fan, \& Zhao. 2011).

\section{Statistical Analysis}

Data were extracted during the landing phase. The average of three trials in each recording block was calculated for each subject. Normality of the data was assessed using a Shapiro-Wilk test. A mixed model analysis of variance (Anova) with heights $(30 \mathrm{~cm}$ and $60 \mathrm{~cm}$ ) and joints (hip, knee, ankle) as the within factors (repeated measures effect), and with the groups (traceurs and untrained) as the between factor (group effect). The dependent variables were the time duration of the landing phase, the configuration at initial contact with the ground, the range of motion, the 
torque, the power and the mechanical work of the studied lower joints: hip, knee and ankle. The threshold level of significance was set to $p \leq .05$. Significant effects were evaluated with correlated and independent t-tests using the Bonferroni correction. Two correlated paired t-tests $(\mathrm{p} / 2)$ were computed to assess the effect of dropping from a height of 30 and of $60 \mathrm{~cm}$ on the assessed variables (untrained $30 \mathrm{~cm}$ vs untrained $60 \mathrm{~cm}$, precision $30 \mathrm{~cm}$ vs precision $60 \mathrm{~cm}$ ). Similarly two independent t-tests $(\mathrm{p} / 2)$ were computed to compare the assessed variables of untrained trials with each of the parkour trials at the same height (untrained $30 \mathrm{~cm}$ vs precision 30 $\mathrm{cm}$, untrained $60 \mathrm{~cm}$ vs precision $60 \mathrm{~cm}$ ).

\section{Results}

\section{Landing phase duration}

The landing phase duration was significantly longer in the Parkour landing $(p<0.001)$. In fact, for both heights the duration of the Parkour landings was around twice the duration of the untrained landings (Table 1).

\section{Landing type and range of motion}

Traceurs executed a soft landing. The knee joint was flexed up to 116 degrees $(30 \mathrm{~cm})$ and 129 degrees $(60 \mathrm{~cm})$ in the precision technique, while untrained participants landed stiffly (up to 65 degrees and 84 degrees respectively). The joint RoM was significantly different between populations and it was significantly different among joints. There was a significant interaction between joints and groups indicating that the RoM of joints changes differently in each group (Table 1). 
Table 1. Means (SD) of kinematic parameters assessed of the dominant leg. Notation. T, time; H, hip flexion; K, knee flexion; A, ankle plantar-flexion; S, total knee flexion from anatomical pose.

\begin{tabular}{|c|c|c|c|c|}
\hline & \multicolumn{2}{|c|}{ Free } & \multicolumn{2}{|c|}{ Precision } \\
\hline & $30 \mathrm{~cm}$ & $60 \mathrm{~cm}$ & $30 \mathrm{~cm}$ & $60 \mathrm{~cm}$ \\
\hline \multicolumn{5}{|c|}{ Landing phase duration (s) } \\
\hline $\mathrm{T}$ & $.15(.03) \dagger$ & $.14(.04) \dagger$ & $.33(.08)$ & $.33(.09)$ \\
\hline \multicolumn{5}{|c|}{ Joint angle at initial contact with the ground (deg) } \\
\hline $\mathrm{H}$ & $2.9(9.2) \dagger$ & $2.2(11.4) \dagger$ & $25.6(8.2)$ & $23.5(9.4)$ \\
\hline $\mathrm{K}$ & $17.8(3.3) * \dagger$ & $22.4(3.6) \dagger$ & $32.1(5.2)$ & $33.7(5.6)$ \\
\hline A & $19.1(10.7)$ & $21.8(10.2)$ & $21.7(10.8)$ & $24.8(9.1)$ \\
\hline \multicolumn{5}{|c|}{ Joint range of motion during the landing phase (deg) } \\
\hline $\mathrm{H}$ & $25.2(9.4) * \dagger$ & $42.5(18.9)$ & $48.1(8.6) *$ & $59.0(8.2)$ \\
\hline $\mathrm{K}$ & $47.0(5.8) * \dagger$ & $61.3(9.4) \dagger$ & $84.1(16) *$ & $95.6(13)$ \\
\hline A & $43.1(3.8) *$ & $50.1(5.0)$ & $48.9(8.9)^{*}$ & $54.4(9.0)$ \\
\hline \multicolumn{5}{|c|}{ Knee range of motion (deg) } \\
\hline $\mathrm{S}$ & 64.8 & 83.7 & 116.2 & 129.3 \\
\hline
\end{tabular}

Means (SD) of kinematic parameters assessed of the dominant leg. Notation. T, time; H, hip

flexion; K, knee flexion; A, ankle plantar-flexion; $S$, total knee flexion from anatomical pose.

*landing from $30 \mathrm{~cm}$ significantly different from landing from $60 \mathrm{~cm}$ for the same trial $(\mathrm{p} \leq .025)$.

$\dagger$ free trial significantly different from precision trial for the same height $(\mathrm{p} \leq .025)$.

\section{Energy dissipation}

The energy dissipation was significantly higher in Parkour landing and it was significantly different between joints. In the Parkour landings, the knee was always the most important contributor for energy dissipation compared to the hip $(p<.001)$ and ankle $(p<.001)$, around twice the contribution of both summed together. The hip and ankle shared equally the rest of the total energy dissipated by the lower-limbs. In the untrained landings, the mechanical energy for dissipation in the hip was significantly less than in the knee $(p<.001)$ and the ankle $(p<.001)$. 
Only the mechanical energy at the hip $(p<.001)$ and knee $(p<.01)$ were significantly higher in Parkour landings compared to untrained landings. The hip worked also in concentric mode (Figure 2 and Table 2).
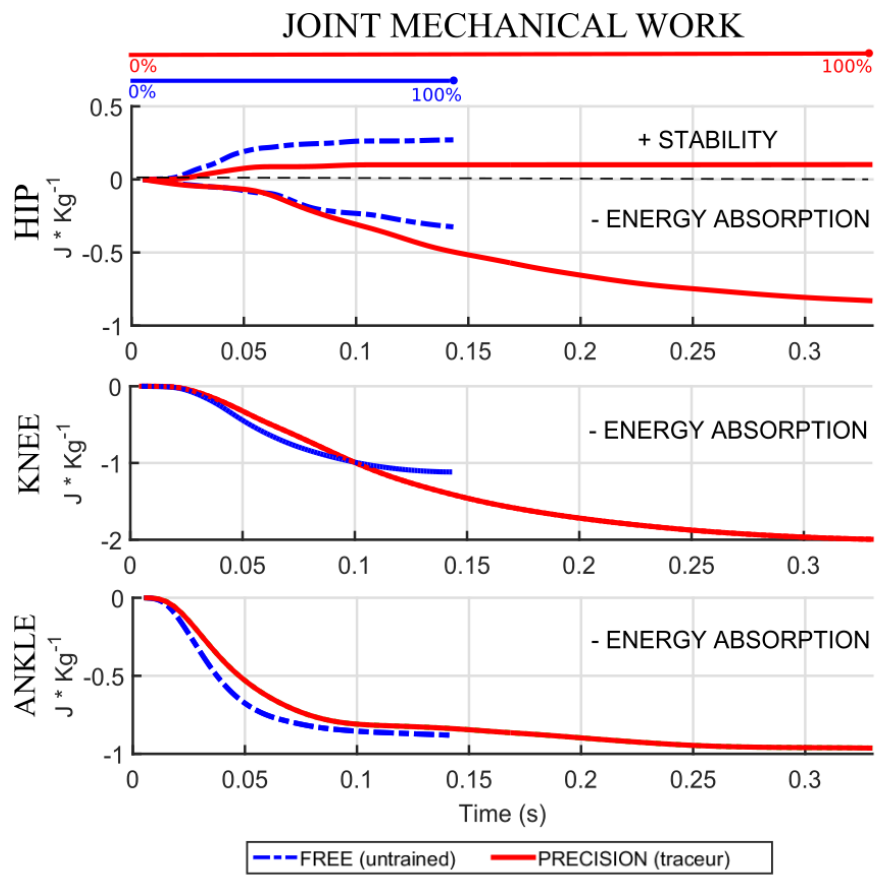

Figure 2. Representative joint work profiles of the dominant leg for trials from $60 \mathrm{~cm}$ drop height. In blue a representative untrained trial and in red a representative precision trial.

\section{Body configuration at IC}

The hip, knee and ankle joint angles overall effect was not significantly different between both groups. However there was a significant interaction between the joints and groups indicating that the joint angles at IC were affected by the group type. Moreover joints were significantly different among themselves (Table 3). 
Table 2. Means (SD) of energetic parameters assessed for the dominant leg. Notation. HE; hip eccentric, KE, knee eccentric; $\mathrm{AE}$, ankle eccentric.

\begin{tabular}{lcccc}
\hline & \multicolumn{2}{c}{ Free } & \multicolumn{2}{c}{ Precision } \\
\multicolumn{2}{c}{$\mathbf{3 0} \mathbf{~ c m}$} & $\mathbf{6 0} \mathbf{~ c m}$ & $\mathbf{3 0} \mathbf{~ c m}$ & $\mathbf{6 0} \mathbf{~ c m}$ \\
\hline \multicolumn{2}{l}{ Mechanical work } & $\left(\mathbf{J} \cdot \mathbf{K g}^{-1}\right)$ \\
$\mathrm{HE}$ & $.23(.1) \dagger$ & $.32(.3) \dagger$ & $.53(.2) *$ & $.83(.3)$ \\
$\mathrm{KE}$ & $.72(.2) * \dagger$ & $1.12(.4) \dagger$ & $1.26(.5) *$ & $1.99(.7)$ \\
$\mathrm{AE}$ & $.85(.2) \dagger$ & $.88(.3)$ & $.61(.1) *$ & $.96(.3)$ \\
\multicolumn{2}{l}{ Work contribution to energy dissipation per joint (\%) } \\
$\mathrm{HE}$ & $12.2(4.9) \dagger$ & $13.1(8.6)$ & $22.9(7.4)$ & $22.4(7.6)$ \\
$\mathrm{KE}$ & $40.4(9.3)$ & $48.1(11.6)$ & $51.3(9.0)$ & $52.5(7.2)$ \\
$\mathrm{AE}$ & $47.4(9.1) * \dagger$ & $38.8(7.4) \dagger$ & $25.8(4.9)$ & $25.1(4.2)$ \\
\hline
\end{tabular}

Means (SD) of energetic parameters assessed for the dominant leg. Notation. HE; hip eccentric, KE, knee eccentric; AE, ankle eccentric.

*landing from $30 \mathrm{~cm}$ significantly different from landing from $60 \mathrm{~cm}$ for the same trial $(\mathrm{p} \leq .025)$.

$\dagger$ free trial significantly different from precision trial for the same height $(\mathrm{p} \leq .025)$.

\section{Ground reaction forces, Power and Torque}

All GRF components were lower in parkour landings than in untrained landings (Table 3). The joint torques and power peaks were significantly lower in Parkour landings than in untrained landings. The joint torques were significantly different among joints as well as the joint power. The knee extensor $(p<.001)$, the hip extensor $(p<.05)$ and the ankle plantar-flexor $(p<.01)$ torques were significantly higher in untrained technique than in precision technique. The hip and knee power were higher in untrained landings although only the ankle power was significantly higher $(p<.0001)$ (Figure 3 and Table 3$)$. 
Table 3. Means (SD) of dynamic parameters assessed for the dominant leg. Notation. HE; hip extension, KF, knee flexion; AP, ankle plantar-flexion.

\begin{tabular}{|c|c|c|c|c|}
\hline & \multicolumn{2}{|c|}{ Untrained } & \multicolumn{2}{|c|}{ Precision } \\
\hline & $30 \mathrm{~cm}$ & $60 \mathrm{~cm}$ & $30 \mathrm{~cm}$ & $60 \mathrm{~cm}$ \\
\hline \multicolumn{5}{|c|}{ Peak force $\left(\mathrm{N} \cdot \mathrm{Kg}^{-1}\right)$} \\
\hline ML & $1.8(.70) \dagger$ & $2.2(1.0) \dagger$ & $0.9(.4)$ & $1.3(.5)$ \\
\hline AP & $3.2(10) \dagger$ & $4.4(1.4) \dagger$ & $2.1(.5) *$ & $2.7(.5)$ \\
\hline V & $17.8(4.3) \dagger$ & $22.2(4.7) \dagger$ & $10.3(1.8) *$ & $13.3(1.6)$ \\
\hline $\mathrm{N}$ & $19.6(4.5) \dagger$ & $23.9(5.3) \dagger$ & $10.8(1.8) *$ & $14.0(2.1)$ \\
\hline \multicolumn{5}{|c|}{ Peak joint torque $\left(\mathrm{N} \cdot \mathrm{m} \cdot \mathrm{Kg}^{-1}\right)$} \\
\hline $\mathrm{HE}$ & $2.18(.4) \dagger$ & $2.45(.7)$ & $1.61(.5)$ & $1.82(.4)$ \\
\hline $\mathrm{KF}$ & $1.84(.3) * \dagger$ & $2.41(.5) \dagger$ & $1.50(.2) *$ & $1.90(.3)$ \\
\hline APF & $1.61(.3) *$ & $1.98(.3)$ & $1.31(.2) *$ & $1.67(.3)$ \\
\hline \multicolumn{5}{|c|}{ Peak joint power $\left(\mathrm{W} \cdot \mathrm{Kg}^{-1}\right)$} \\
\hline $\mathrm{HE}$ & $12.4(5.0)$ & $16.7(10.2)$ & $8.3(3.3) *$ & $12.4(4.5)$ \\
\hline KF & $15.4(5.9) *$ & $27.4(11.6)$ & $11.8(3.2) *$ & $19.5(4.0)$ \\
\hline APF & $24.6(6.0) * \dagger$ & $36.8(7.2) \dagger$ & $12.9(5.6)$ & $23.4(7.0)$ \\
\hline
\end{tabular}

Means (SD) of kinetic and dynamic parameters assessed for the dominant leg. Notation. ML, medial lateral; $A P$, antero posterior; $V$, vertical; $N$, norm of the force. $H E$, hip extension; $K F$, knee flexion; $A P F$, ankle plantar-flexion

*landing from $30 \mathrm{~cm}$ significantly different from landing from $60 \mathrm{~cm}$ for the same trial $(\mathrm{p} \leq .025)$.

$\dagger$ free trial significantly different from precision trial for the same height $(\mathrm{p} \leq .025)$.

\section{Height effect}

The landing phase duration was not significantly different between $30 \mathrm{~cm}$ and $60 \mathrm{~cm}$. The joint range of motion increased significantly with height. Moreover, the height interacted significantly with the joints and thus the RoM of joints changed differently when the height increased. The energy dissipation increased significantly with height. In the Parkour landings, total 
energy dissipation increased significantly with height $(p<0.001)$, while individual joint energy contribution (in \%) for dissipation was not significantly different. The hip was significantly more flexed in Parkour landings at IC than in untrained landings at $30 \mathrm{~cm}(p<.001)$. With the increase of the height, the joint angles of traceurs did not change significantly while untrained participants modified their joint angles significantly $(p<.045)$. Ground reaction forces, joint torques and power were significantly higher at $60 \mathrm{~cm}$ than at $30 \mathrm{~cm}$.
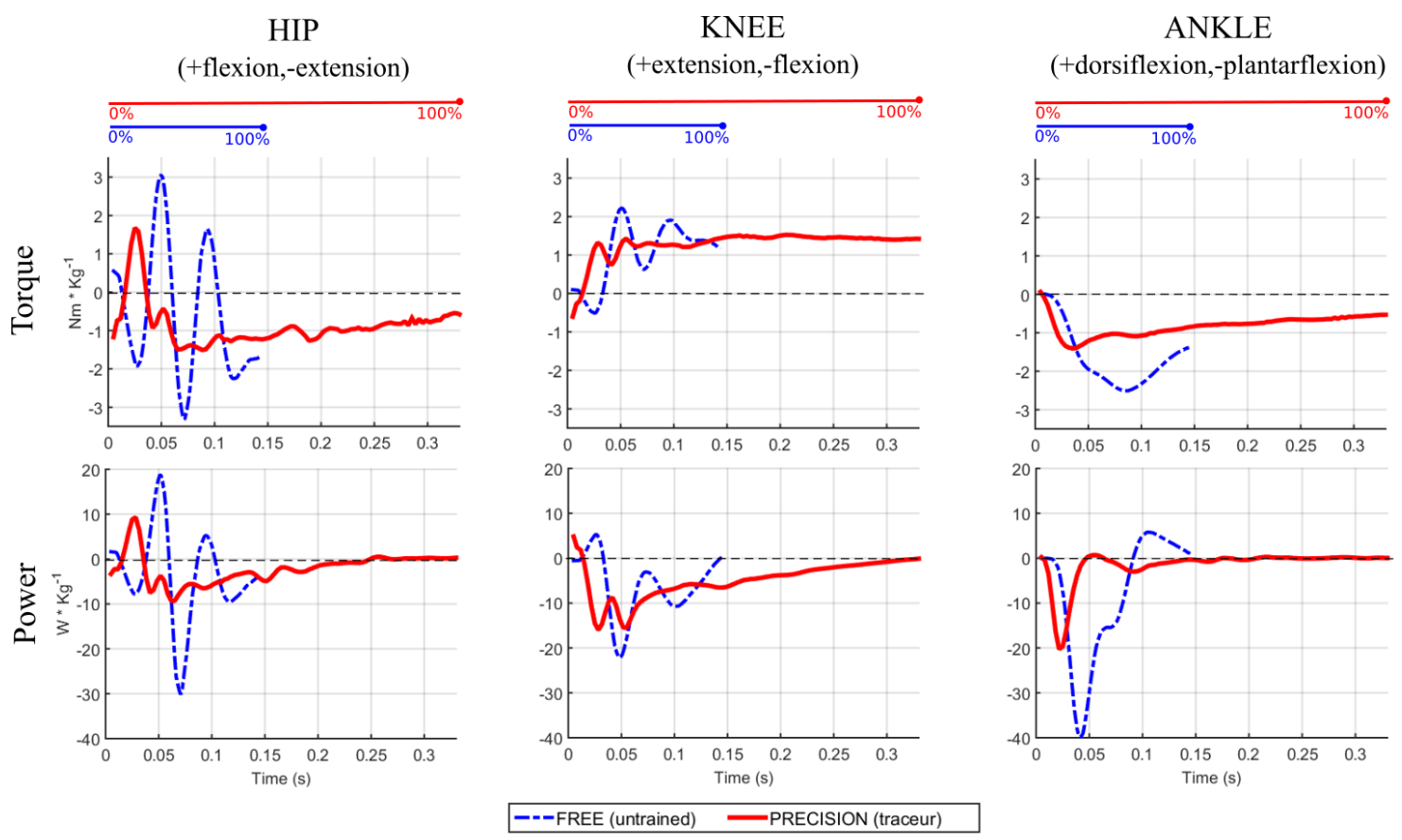

Figure 3. Representative joint torque and power landing profiles of the dominant leg for trials from $60 \mathrm{~cm}$ drop height. In blue a representative untrained trial and in red a representative precision trial.

\section{Discussion}

In this research, kinematics, dynamics and energetics of Parkour precision during landing were presented for the first time. The Parkour precision technique appeared to lower the GRF, joint torques and power. This result provides interesting cues that can be of great interest for sports 
where landing dynamics are high. The configuration at IC, the landing phase duration and the joint mechanical energy dissipation appear to be invariants of the technique. Moreover, the knee appeared to be the principal mechanism for energy dissipation in Parkour landings. Thus, our results could be used to enhance Parkour training and performance. Moreover, results can be also used to understand new ways in which sport practitioners can land in order to prevent injuries like in gymnastic where the athletes tend to land with stiffer landings techniques (Christoforidou et al., 2017).

Experiments show that in precision technique, when landing and stabilizing, traceurs extend the landing phase duration, flex more the lower extremity joints and increase the mechanical energy dissipated by the lower limbs. This strategy seems to help them landing smoothly and reducing the peaks of joint torques and joint power. The increase of jump height did not affect the strategy in terms of joint angles and joint contribution to energy dissipation.

The landing phase duration, the range of motion and the way traceurs dissipate the energy of the impact appear to be important parameters in the execution of the Parkour precision landings. Interestingly, the precision technique induces more active energy dissipation than untrained landings which is less efficient in terms of energy transformation, which requires conditioning of extensor muscles. However, by increasing the landing phase duration, the mechanical joint energy and the RoM of the lower-limbs, traceurs are able to distribute torques along the landing phase duration in order to reduce the associated peak demands and to damp the impact forces.

In untrained technique, we observed that the ankle plantar-flexors and the knee extensors are the main mechanisms of energy dissipation through negative mechanical work, which is similar to previous results reported in the literature for stiff landing (Devita, \& Skelly, 1992; Zhang, Bates, \& Dufek, 2000). Conversely, in Parkour trials the knee accounts for half of the mechanical work 
needed for energy dissipation while the hip and ankle share uniformly the rest of the energy dissipated within the lower-limbs. This result highlights the importance of the knee joint for energy dissipation in the Parkour technique, and a compromise for sharing equally the loads with the hip and ankle joints.

At IC, traceurs land with the hip and knee more flexed than untrained participants. It has been reported (Cortes et al., 2007) that when untrained participants land on their forefoot only, they show significantly lower knee and hip flexion compared to landings that include heel contact. Moreover, in the same study, it was suggested that the forefoot technique requires the participants to have a straighter position at initial ground contact to stabilize. However, for traceurs executing precision landing, stability was significantly higher compared to untrained participants (Maldonado, Bitard, Watier, \& Soueres, 2015) suggesting that a straight pose does not necessarily increases stability. We suggest that, in the case of precision landings, the body configuration at IC allows traceurs to land with their center of mass closer to the center of the base of support. Moreover, landing on their forefoot and with the body more flexed, allows traceurs to progressively flex their lower-joints in order to damp the impact and to control their balance using eccentric loading.

Considering inverse dynamics in the untrained trials, our results are consistent with those previously published (Devita, \& Skelly, 1992; Mccaw et al., 2013; McNitt-Gray, 1993). Our results show that the hip also work in concentric mode at the beginning of the landing phase. It has been suggested (Devita, \& Skelly 1992) that the hip eccentric mode is used to dissipate the impact whereas the concentric mode is used to keep the upper body aligned over the legs. In the present study, upper trunk stability was achieved by both eccentric and concentric modes because flexors and extensors were used to maintain stability (landing from a horizontal distance of $50 \mathrm{~cm}$ ). This 
phenomenon was principally observed in untrained landings. In the precision trials, the concentric mode is significantly less used than in untrained trials, presumably because the landing of traceurs is more stable due to a better postural control.

The knee extensor torque was significantly higher in the untrained trials than in the precision trials, maybe because extending the landing phase duration allows traceurs to redistribute torques along the time and thus decrease the peak joint torques and peak joint power demands. Moreover, traceurs are able to reduce the GRF peak more significantly than untrained participants (Puddle, \& Maulder, 2013; Standing, \& Maulder, 2015) which might influence the joint torque level. In the present study, peak GRF of untrained and parkour landings were similar to those reported in the literature (Puddle, \& Maulder 2013; Standing, \& Maulder 2015; Devita, \& Skelly, 1992; Zhang, Bates, \& Dufek, 2000; McNitt-Gray, 1993) confirming that in Parkour landings the impact GRF is reduced. Moreover, we showed that parkour techniques permit to decrease anteroposterior and medial-lateral forces inducing less stresses at the joints. This may also help traceurs to land softly and control their balance without significantly deviating their center of mass.

Having no contact the heel with the ground in Parkour landings may increase the lever arm between GRF and ankle joint center but does not imply higher torques nor higher power than those generated at the ankle joint by untrained participants to counteract the induced rotational motion around the ankle. However, for important height, traceurs cannot continue rotating their lower extremity joints, higher torques might be necessary to counteract the motion. The ankle plantarflexor peak power is significantly higher in untrained trials probably because of the heel contact with the ground, which may have induced higher peak angular velocity of the ankle and also combined with the fact that the GRF were higher during untrained landings. Furthermore, it has been shown (Grosprêtre, \& Lepers, 2016) that eccentric torque capability was greater in traceurs 
than in power athletes and gymnasts. In the present study, we observed that regardless of this capability, Parkour techniques induce less peak torques and peak power at the joints.

Mechanical work, torques and power increased with height, as reported in literature, essentially because the duration of the landing phase remains constant for both jumping heights, but the energy to dissipate is higher (Yeow, Lee, \& Goh, 2010). Similarly, precision and untrained techniques induced significantly more RoM of the hip, knee and ankle joints. The reason seems to be due to the initial landing velocity, which is higher at $60 \mathrm{~cm}$ and may have induced more flexion of the joints after ground contact. For untrained trials at $60 \mathrm{~cm}$, RoM and initial joint angles reported in the literature (Decker, Torry, Wyland, Sterett, \& Richard, 2003) were similar to the results presented here. In Parkour trials, the joints configuration at IC and the proportion of individual joint mechanical energy contribution for dissipation did not change significantly. The invariance of these parameters seems to reflect their importance in the execution of Parkour precision landings.

It has been reported that a stiffer landing could manifest to patellar tendinopathy when peak joint velocities and torques increase (Bisseling et al., 2007). Therefore, Parkour coaches should closely monitor the landing strategy and the joint load frequency to reduce the patellar tendon loading and the risk of injury. Hip flexion at IC and no contact of the heel with the ground seem to help traceurs to execute soft landings (Devita, \& Skelly 1992) by increasing the lower-joints flexion. However, high impact pressure concentrated in metatarsal bones and high vertical reaction forces may cause metatarsal fractures (Kavanaugh, Brower, \& Mann 1978). When possible (sometimes the surface imposes the landing technique), traceurs might use other Parkour landing techniques such as the roll landing technique (Puddle, \& Maulder 2013) from higher heights in order to lower the GRF. Nevertheless, more studies comparing the precision with the roll technique 
from different heights are needed to assess up to which height the precision landing is safe. Moreover, when the landing height is increased, ankle taping could be helpful to enhance peak plantar-flexion strength (Hopper, Grisbrook, Finucane, \& Nosaka, 2014). In the Parkour community, an unwritten rule suggesting a maximum knee flexion of 90 degrees in landings is commonly used. However, in this study traceurs exceeded 90 degrees and this strategy appeared to be beneficial compared to landings performed with less than 90 degrees because it helps to smooth the mechanical parameters during landing impact. Furthermore, for optimizing the performance (considering the eccentric force-velocity relationship of the muscles) during the landing phase, extensor muscles should be warmed up and intense fatigue should be prevented. This may help traceurs to enhance and maintain their capacity of developing the required eccentric torques (De Ruiter, \& De Haan, 2001). Moreover, extensor muscles should be conditioned for executing Parkour landings taking into account that the knee accounted for half of the energy dissipated by the lower-limbs.

A limitation of this research is that traceurs were recorded inside a laboratory for limited heights and horizontal distances, which differs from natural Parkour practice. In fact, for safety reasons, jump height was limited because our protocol included untrained participants. However, higher drops with longer horizontal distances might induce higher antero-posterior forces and different biomechanics of the precision landing. Probably, the strategy will be adapted to maintain stability and dissipate the energy of the impact safely. Thus, an interesting direction for future work might be the study of such landings conditions and the performance of other Parkour landings such as the roll technique. 


\section{References}

Bisseling R.W., Hof A.L., Bredeweg S.W., Zwerver J., \& Mulder T. (2008). Are the Take-off and Landing Phase Dynamics of the Volleyball Spike Jump Related to Patellar Tendinopathy?. Br J Sports Med; 42, 483-489.

Bisseling R.W., Hof A.L., Bredeweg S.W., Zwerver J., \& Mulder T. (2007). Relationship between Landing Strategy and Patellar Tendinopathy in Volleyball. Br J Sports Med; 41, 1-6.

Cazenave N., \& Michel G. (2008). Conduites À Risques et Variation de L'estime de Soi Chez Les Adolescents : L'exemple Du Parkour. Ann Med-Psychol 166, 875-881.

Christoforidou A., Patikas D.A., Bassa E., Paraschos I.,Lazaridis S.,Christoforidis C., \& Kotzamanidis C. (2017). Landing from Different Heights: Biomechanical and Neuromuscular Strategies in Trained Gymnasts and Untrained Prepubescent Girls. Journal of Electromyography and Kinesiology, 32, 1-8.

Cortes N., Onate J., Abrantes J., Gagen L., Dowling E., \& Van Lunen B. (2007). Effects of Gender and FootLanding Techniques on Lower Extremity Kinematics during Drop-Jump Landings. J Appl Biomech, 23, 289299.

De Ruiter C.J., \& De Haan A. (2001). Similar Effects of Cooling and Fatigue on Eccentric and Concentric ForceVelocity Relationships in Human Muscle. J Appl Physiol; 90, 2109-2116.

Decker M.J., Torry M.R., Wyland D.J., Sterett W.I., \& Richard Steadman J. (2003). Gender differences in lower extremity kinematics, kinetics and energy absorption during landing. Clin Biomech, 18, 662-669.

Delp S.L., Loan J.P., Hoy M.G., Zajac F.E., Topp E.L., \& Rosen J.M. (1990). An interactive graphics-based model of the lower extremity to study orthopaedic surgical procedures. IEEE Trans Biomed Eng; 37, 1940-1950.

Delp S.L., Anderson F.C., Arnold A.S., Loan J.P., Habib A., John C.T., Guendelman E., \& Thelen D.G. (2007). OpenSim: open-source software to create and analyze dynamic simulations of movement. IEEE Trans Biomed Eng, 54, 1940-1950.

Devita P., \& Skelly W.A. (1992). Effect of landing stiffness on joint kinetics and energetics in the lower extremity. Med Sci Sports Exerc, 24, 108-115.

Dumas R., Chèze L., \& Verriest JP. (2007). Adjustments to McConville et Al. and Young et al. body segment inertial parameters. $J$ Biomech, 40, 543-553.

Gittoes M.J., \& Irwing G. (2012). Biomechanical approaches to understanding the potentially injurious demands of gymnastic-style impact landings. Sports Med Arthrosc Rehabil Ther Technol, 4, 4.

Gilchrist P., \& Wheaton B. (2011). Lifestyle sport, public policy and youth engagement: examining the emergence of parkour. Int J Sport Pol and Pol, 3, 109-131.

Grosprêtre S., \& Lepers R. (2016). Performance characteristics of Parkour practitioners: Who are the traceurs? Eur. 
J. Sport Sci, 16, 526-535.

Hopper D.M., Grisbrook T.L., Finucane M., \& Nosaka K. (2014). Effect of ankle taping on angle and force matching and strength of the plantar flexors. Phys Ther Sport, 15, 254-260.

Kavanaugh J.H., Brower T.D., \& Mann R.V. (1978). The Jones fracture revisited. J Bone Joint Surg Am. 60, 776782.

Kidder J.L. (2012). Parkour, The Affective Appropriation of Urban Space, and the Real/Virtual Dialectic. City Community, 11, 229-253.

Kristianslund E., Krosshaug T., \& van den Bogert A.J. (2012). Effect of low pass filtering on joint moments from inverse dynamics: implications for injury prevention. $J$ Biomech, 45, 666-671.

Maldonado G., Bitard H., Watier B., \& Souères P. (2015). Evidence of dynamic postural control performance in parkour landing. Comput Methods Biomech Biomed Engin, 18, 1994-1995.

Marchetti P.H., Junior D.A.L., Soares E.G., Silva F.H., Uchida M.C., \& Teixeira L.F.M. (2012). Differences in Muscular Performance between Practitioners and Non Practitioners of Parkour. Int J Sports Sci, 2, 36-41.

Mccaw S.T., Gardner J.K., Stafford L.N., \& Torry M.R. (2013). Filtering ground reaction force data affects the calculation and interpretation of joint kinetics and energetics during drop landings. $J$ Appl Biomech, 29, 804 809.

McNitt-Gray J.L. (1993). Kinetics of the lower extremities during drop landings from three heights. $J$ Biomech, 26, $1037-1046$.

Niu W., Wang Y., He Y., Fan Y., \& Zhao Q. (2011). Kinematics, kinetics, and electromyogram of ankle during drop landing: a comparison between dominant and non-dominant limb. Hum Mov Sci, 30, 614-623.

Puddle D.L., \& Maulder P.S. (2013). Ground reaction forces and loading rates associated with parkour and traditional drop landing techniques. J Sports Sci Med, 12, 122-129.

Rosen A.B., Ko J., Simpson K.J., Kim S.H., \& Brown C.N. (2015). Lower Extremity Kinematics During a Drop Jump in Individuals With Patellar Tendinopathy. Orthop J Sports Med, 3, 2325967115576100.

Standing R.J., \& Maulder P.S. (2015). A Comparison of the Habitual Landing Strategies from Differing Drop Heights of Parkour Practitioners ( Traceurs ) and Recreationally Trained Individuals. J Sports Sci Med, 14, 723-731.

Wanke E.M., Thiel N., Groneberg D.A., \& Fischer A. (2013). Parkour--'art of Movement' and Its Injury Risk. Sportverletz Sportschaden, 27, 169-76.

Winter D. (2009). Biomechanics and Motor Control of Human Movement. John Wiley \& Sons, Inc, 70-72.

Wu G., Siegler S., Allard P., Kirtley C., Leardini A., Rosenbaum D., Whittle M., Schmid O., \& Stokes I. (2002). ISB 
Recommendation on Definitions of Joint Coordinate System of Various Joints for the Reporting of Human Joint motion—Part I: Ankle, Hip, and Spine.” J Biomech, 35, 543-548.

Yeow C.H., Lee P.V., \& Goh J.C. (2009). Effect of landing height on frontal plane kinematics, kinetics and energy dissipation at lower extremity joints. $J$ Biomech, 42, 1967-1973.

Yeow C.H., Lee P.V., \& Goh J.C. (2010). Sagittal Knee Joint Kinematics and Energetics in Response to Different Landing Heights and Techniques. Knee, 17, 127-131.

Zhang S.N., Bates B.T., \& Dufek J.S. (2000). Contributions of lower extremity joints to energy dissipation during landings. Med Sci Sports Exerc, 32, 812-819. 